\title{
Normalização dos níveis séricos de ácido ascórbico por suplementação com suco de acerola (Malpighia glabra L.) ou farmacológica em idosos institucionalizados ${ }^{1}$
}

\author{
Normalize the ascorbic acid serum levels the ascorbic acid of \\ the for suplementation with acerola juice (Malpighia glabra L.) \\ and the pills, institutionalized elderly
}

Flávia Queiroga ARANHA²

Luiza Sônia Asciutti MOURA ${ }^{3}$

Mônica Oliveira da Silva SIMÕES 3

Zianne Farias BARROS ${ }^{4}$

Ivana Versianny Lira QUIRINO ${ }^{4}$

Juliana Cavalcanti METRI ${ }^{4}$

Jefferson Carneiro de BARROS ${ }^{4}$

\section{R E S U M O}

\section{Introdução}

Este estudo investigou o tempo necessário de suplementação com vitamina C, para a normalização dos níveis séricos em idosos com deficiência dessa vitamina e comparar o efeito da vitamina natural do suco de acerola (Malpighia glabra L.) com o da vitamina na forma de fármaco.

\section{Métodos}

Foram estudados 37 idosos institucionalizados do município de João Pessoa, Paraíba, Brasil, divididos em 3 grupos: Grupo I - controle, Grupo II - suplementação com o suco de acerola e Grupo III - suplementação com fármaco. A metodologia empregada consistiu na dosagem sérica de ácido ascórbico e na verificação do

\footnotetext{
${ }^{1}$ Artigo elaborado a partir da dissertação de F.Q. ARANHA, intitulada "Investigação do tempo necessário de suplementação com vitamina C, do suco de acerola e do farmaco, necessário para normalizar os níveis séricos de ácido ascórbico em idosos institucionalizados de João Pessoa-PB". Centro de Tecnologia, Curso de Pós-Graduação em Ciência e Tecnologia de Alimentos, Universidade Federal da Paraíba, 1997. 94p.

2 Departamento de Educação, Instituto de Biociências, Universidade Estadual Paulista, Campus Botucatu. Distrito Rubião Júnior, s/n, Botucatu, SP, Brasil. Correspondência para/Correspondence to: F.Q. ARANHA. E-mail: aranha@ ibb.unesp.br

3 Departamento de Nutrição, Centro de Ciências da Saúde, Universidade Federal da Paraíba. João Pessoa, PB, Brasil.

4 Centro de Ciências Biológicas e da Saúde, Universidade Estadual da Paraíba. Campina Grande, PB, Brasil.
} 
consumo alimentar por inquérito dietético. Constatou-se um aumento significativo $(p<0,05)$ nas médias dos

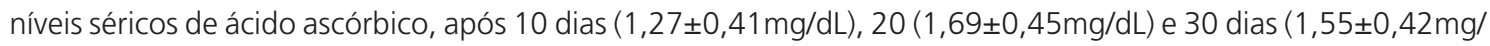
$\mathrm{dL})$ de suplementação aos valores iniciais $(0,38 \pm 0,28 \mathrm{mg} / \mathrm{dL})$. No $10^{\circ}$ dia de suplementação, os idosos suplementados com suco de acerola apresentaram níveis significativamente mais elevados $(1,41 \pm 0,43 \mathrm{mg} / \mathrm{dL})$ do que aqueles que foram suplementados com comprimidos $(1,03 \pm 0,25 \mathrm{mg} / \mathrm{dL})$.

\section{Conclusão}

Considerando-se que, no $20^{\circ}$ dia, o efeito da suplementação foi satisfatório para a normalização dos níveis séricos daqueles indivíduos, esse tempo poderia ser utilizado para idosos em geral e, em especial, para aqueles que vivem em instituições destinadas a idosos carentes, sendo o suco de acerola um suplemento indicado por ser um produto natural e de fácil aquisição.

Termos de indexação: vitamina C, suplementação, idoso, institucionalizados, acerola (Malpighia glabra, L.), fármaco.

\section{A B S T R A C T}

\section{Introduction}

Thirty-seven elderly citizens, deficient in vitamin C and institutionalized in the city of João Pessoa/Paraibal Brazil, were studied with the objective of investigating the period of vitamin C supplementation necessary to normalize their blood serum levels.

\section{Methods}

The study also compared the efficiency of the natural vitamin, supplied in the form of West Indian cherry juice, (Malpighia glabra L.) to that of the pharmaceutical product (tablets). The aged citizens were divided into 3 groups: Group I - control, Group II - supplemented with West Indian cherry juice, and Group III - supplemented with tablets. The methodology applied consisted of dosing the serum vitamin C levels and making a dietary enquiry to determine food consumption.

\section{Results}

A significant increase $(p<0.05)$ in the mean serum ascorbic acid levels was shown after $10(1.27 \pm 0.41 \mathrm{mg} / \mathrm{dL})$, $20(1.69 \pm 0.45 \mathrm{mg} / \mathrm{dL})$ and $30(1.55 \pm 0.42 \mathrm{mg} / \mathrm{dL})$ days of supplementation, as compared to the initial values $(0.38 \pm 0.28 \mathrm{mg} / \mathrm{dL})$. On the $10^{\text {th }}$ day of supplementation, those supplemented with West Indian cherry juice showed levels significantly higher $(1.41 \pm 0.43 \mathrm{mg} / \mathrm{dL})$ than those supplemented with tablets $(1.03 \pm 0.25 \mathrm{mg} / \mathrm{dL})$.

\section{Conclusion}

On the $20^{\text {th }}$ day, the supplementation had satisfactorily normalized the blood serum levels of the institutionalized aged citizens. Therefore, this amount of time could be considered as the necessary supplementation period for the aged in general. Moreover, especially, for those who live in institutions with limited resources, West Indian cherry juice should be the supplement of choice, since it is a natural and affordable product.

Index terms: vitamin C, supplement, elderly, institutionalized citizens, West Indian cherry (Malpighia glabra L.), tablets.

\section{N T R O D U Ç Ã O}

O aumento da população idosa, em todo o mundo, é uma realidade. No Brasil, essa realidade não é diferente: pelas estatísticas do Instituto Brasileiro de Geografia e Estatística (IBGE) de 2000, temos atualmente cerca de 14,5 milhões de pessoas com idade igual ou acima de 60 anos $^{1}$. 
De acordo com Aranha et al. ${ }^{2}$ durante o processo de envelhecimento ocorrem alterações na maioria das funções orgânicas ligadas à nutrição.

Considerando-se que o poder aquisitivo dos indivíduos de baixa renda não lhes permite períodos longos de suplementação e que as instituições para idosos sem renda não podem realizar intervenções sistemáticas neste sentido, é importante saber o tempo necessário de suplementação com vitamina $\mathrm{C}$ para que os níveis séricos de ácido ascórbico atinjam a normalidade. O presente trabalho teve como objetivo investigar o tempo necessário de suplementação com vitamina C, para a normalização dos níveis séricos de ácido ascórbico, em idosos institucionalizados do município de João Pessoa, Paraíba, Brasil. Simultaneamente, investigou-se os efeitos das formas de suplementação oferecidas, comparando-se a vitamina natural do suco de acerola com a vitamina sob a forma de fármaco.

\section{CASUÍSTICA E MÉTODOS}

A população estudada envolveu 112 idosos, apresentando idades compreendidas entre 60 e 93 anos, sendo $76(67,8 \%)$ do sexo feminino e $36(32,2 \%)$ do sexo masculino, residentes em cinco instituições da Grande João Pessoa, Paraíba, Brasil. Num primeiro momento, foi mantido um contato com os diretores das instituições, com o propósito de esclarecer os objetivos da pesquisa e obter autorização necessária para a realização do trabalho. Em cada instituição, solicitou-se a relação dos idosos, contendo dados de identificação, sexo e data de nascimento; posteriormente, obteve-se de cada um o consentimento para participar do estudo. Os idosos que foram selecionados para participar do estudo não faziam dietas especiais; foram excluídos os indivíduos não aptos a participar da pesquisa, como os acamados, debilitados e os que apresentavam problemas mentais.

O protocolo do estudo foi previamente aprovado pelo Comitê de Ética do Centro de Ciências da Saúde da Universidade Federal da Paraíba, João Pessoa, Paraíba.
Dos 112 idosos selecionados, 43 apresentaram hipovitaminose C, estando $26(60,47 \%)$ deles com deficiência moderada $(0,20$ a 0,80 mg/dL) e 17 (39,53\%), com deficiência grave $(<0,20 \mathrm{mg} / \mathrm{dL})$. Destes 43 idosos, 6 foram excluídos da amostra: 3 por óbito, 2 por desistência própria e 1 por apresentar diarréia. Restaram, portanto, 37 idosos, dos quais 18 (48,65\%) eram do sexo masculino e 19 (51,35\%) do sexo feminino.

Na distribuição dos idosos por faixa etária, $18(48,65 \%)$ estavam entre 60 e 69 anos; 9 (24,32\%), entre 70 e 79 anos; 8 (21,62\%), entre 80 e 89 anos; 2 (5,41\%), tinham 90 anos ou mais.

A metodologia utilizada envolveu dois tipos de avaliações: bioquímica e dietética. Foram analisados os níveis séricos de ácido ascórbico, logo após a extração do soro; realizou-se dosagem direta de ácido ascórbico, utilizando-se o método espectrofotométrico descrito por Lowry et al. em 1945 e modificado por Costa ${ }^{3}$, que se fundamenta inicialmente na oxidação do ácido ascórbico, pelo cobre, a ácidos dehidroascórbico e dicetogulônico.

Segundo Tsuji et al. ${ }^{4}$, os valores, a partir dos quais se situam os riscos de deficiência vitamínica $C$, são os seguintes: menor de $0,20 \mathrm{mg} / \mathrm{dL}$ - deficiência grave, e de 0,80 a $1,60 \mathrm{mg} / \mathrm{dL}$ - níveis normais. Os níveis séricos de ácido ascórbico compreendidos entre 0,20 a $0,80 \mathrm{mg} / \mathrm{dL}$, correspondem ao intervalo entre os limites de carência grave e de normalidade. Neste estudo, consideraram-se estes níveis como carência moderada, enquanto que os valores iguais ou superiores a $1,60 \mathrm{mg} / \mathrm{dL}$, foram dados como acima do normal.

Para a avaliação dietética foram utilizados o inquérito alimentar - durante sete dias, por pesagem direta no desjejum, almoço, lanche e jantar - e o recordatório alimentar na colação ${ }^{5}$. A aplicação dos inquéritos foi realizada por alunos do curso de nutrição, então bolsistas no projeto de pesquisa, com supervisão de um nutricionista. Utilizaram-se dois tipos de inquérito, devido ao horário em que era servida a colação. Um programa informatizado foi empregado para calcular a ingestão de vitamina $\mathrm{C}$ dos idosos ${ }^{6}$, 
comparando o resultado com as recomendações estabelecidas pela National Research Councir. Os dados coletados no inquérito foram codificados e transcritos para um software, contendo as tabelas de composição química dos alimentos ${ }^{8,9}$.

Para verificar a adequação do consumo de vitamina $C$, pelos idosos, nos alimentos em geral consumidos, foi adotada a metodologia utilizada por Moura ${ }^{10}$, que classifica a ingestão da seguinte maneira: adequada - superior a $80 \%$ das recomendações do NRC; em risco de deficiência - de $50 \%$ a $80 \%$ das recomendações; deficiente - menos de 50\% das recomendações.

\section{Modalidade de Suplementação}

Para a suplementação, a amostra foi determinada aleatoriamente através do sorteio entre os idosos que apresentavam hipovitaminose C; foram organizados três grupos, segundo o tipo de suplementação: grupo I, com 11 idosos, constituintes do controle, os quais não foram suplementados nesse período do estudo; grupo II, com 13 idosos, suplementados com suco de acerola com teor de $500 \mathrm{mg}$ de vitamina $C$ por porção; grupo III, com 13 idosos, suplementados com fármaco de 500mg de vitamina C. A suplementação foi oferecida num período de 30 dias consecutivos, no horário do lanche.

Apenas os idosos que receberam suplementação de suco de acerola e comprimido foram submetidos novamente a uma coleta de sangue para determinação sérica do ácido ascórbico no $10^{\circ}$, no $20^{\circ}$ e no $30^{\circ}$ dias de suplementação. Essas análises foram necessárias para acompanhar o efeito em relação ao tempo de suplementação. Os idosos do grupo controle fizeram análise sérica apenas no tempo zero e no $30^{\circ}$ dia; após esse período, receberam suplementação com suco de acerola, durante 30 dias consecutivos. Ocorreu diferença de resultados, com relação ao número de idosos, devido à impossibilidade de coleta de amostra (sangue), nos dias determinados para o mesmo.
Os dados obtidos, depois de tabulados, foram submetidos às análises estatísticas descritivas e de significância, para as quais foi utilizado o software "SPSS" (Statistical Package for Social Sciences).

RESULTADOSE DISCUSSÃO

\section{Investigação do tempo de suplementação}

Houve relação de dependência entre os níveis séricos de ácido ascórbico e o tempo de suplementação com $500 \mathrm{mg}$ de vitamina C, nos idosos institucionalizados, ocorrendo um aumento do tempo zero ao $10^{\circ}$ e $20^{\circ}$ dias de suplementação; no $30^{\circ}$ dia, foi observado um leve declínio em relação ao $20^{\circ}$ dia, sugerindo talvez uma saturação nos tecidos (Tabela 1) ${ }^{11}$.

Tabela 1. Médias $(\bar{X})$ e desvio-padrões (DP) dos níveis séricos de ácido ascórbico $(\mathrm{mg} / \mathrm{dL})$ nos tempos de suplementação.

\begin{tabular}{lccc}
\hline $\begin{array}{l}\text { Tempo de } \\
\text { Suplementação } \\
\text { (Dias) }\end{array}$ & $\mathrm{n}$ & $\overline{\mathrm{X}}^{*} \pm \mathrm{DP}$ & Variação \\
\hline 0 & 26 & $0,38 \pm 0,28^{\mathrm{a}}$ & $0,05-0,74$ \\
$10^{\circ}$ & 18 & $1,27 \pm 0,41^{\mathrm{b}}$ & $0,57-1,93$ \\
$20^{\circ}$ & 20 & $1,69 \pm 0,45^{\mathrm{c}}$ & $0,78-2,67$ \\
$30^{\circ}$ & 26 & $1,55 \pm 0,42^{\mathrm{c}}$ & $0,78-2,50$ \\
\hline
\end{tabular}

(*) Relação de dependência, estatística $F$ da análise de variância (ANOVA) com uma classificação ( $F=34,70 ; p<0,001)$.

As letras $a, b$ e c na mesma coluna indicam diferença significativa entre os tempos de suplementação $(p<0,05)$.

Moura et al. ${ }^{12}$ observaram que a suplementação com comprimidos de $200 \mathrm{mg}$ de vitamina C, durante 30 dias, corrigiu satisfatoriamente os níveis séricos de ácido ascórbico de idosos franceses institucionalizados de ambos os sexos. Sabe-se que doses moderadas apresentam maior biodisponibilidade. Levine et al. ${ }^{13}$ relataram que dados da biodisponibilidade de vitamina $C$ indicam que doses compreendidas entre $1000 \mathrm{e}$ 2000mg têm biodisponibilidade mais baixa do que 
uma dose de 500mg, sugerindo então que a dose ideal não deve ultrapassar $100 \mathrm{mg} /$ dia.

Após a suplementação, 1 idoso do sexo feminino apresentou carência moderada, podendo-se pensar na hipótese de problemas decorrentes de alterações fisiológicas ou patológicas, em nível individual, acarretando dificuldades na absorção ou aumento da utilização ${ }^{14}$.

A comparação dos resultados entre os sexos, mostrou que as médias dos níveis séricos de ácido ascórbico foram semelhantes no $10^{\circ} \mathrm{dia}$; no $20^{\circ} \mathrm{dia}$, os dados indicam uma tendência de as mulheres apresentarem níveis mais elevados do que os homens, enquanto que, no $30^{\circ} \mathrm{dia}$, verificou-se que os homens apresentaram valores superiores aos das mulheres (Figura 1). Baker apud Costa et al..$^{15}$ relataram que o depósito de ácido ascórbico está diretamente relacionado com a massa magra, havendo, porém, outras variáveis relacionadas com o sexo, como por exemplo as diferenças hormonais. Do mesmo modo, outros autores mostraram que as mulheres apresentaram níveis mais altos de ácido ascórbico do que os homens, apesar dos aportes serem semelhantes ${ }^{12}$.
Há diferença na absorção renal e distribuição de ácido ascórbico entre os sexos.

É interessante notar que, nas mulheres, houve diminuição significativa dos níveis séricos, do $20^{\circ}$ para o $30^{\circ}$ dia, enquanto que, nos homens, houve um aumento constante até o $30^{\circ} \mathrm{dia}$ (Figura 1). Esses fatos sugerem que a saturação orgânica de vitamina $C$, nas mulheres, pode ser mais rápida do que nos homens e/ou que a sua excreção pode ser diferente entre os $\operatorname{sexos}^{12}$. Nesta pesquisa verificou-se que os indivíduos do sexo feminino que receberam comprimidos apresentaram, no $20^{\circ}$ dia, níveis séricos de ácido ascórbico mais elevados do que os do sexo masculino, enquanto que, no $30^{\circ}$ dia, os idosos do sexo masculino, suplementados com suco de acerola, tiveram níveis mais elevados do que os do sexo feminino (Figura 1).

Aplicando-se o teste-T, evidenciou-se que, no $10^{\circ}$ dia de suplementação, os níveis séricos de ácido ascórbico dos idosos que receberam suco de acerola apresentaram-se significativamente superiores àqueles dos idosos que receberam comprimido, enquanto que, nos demais dias, os

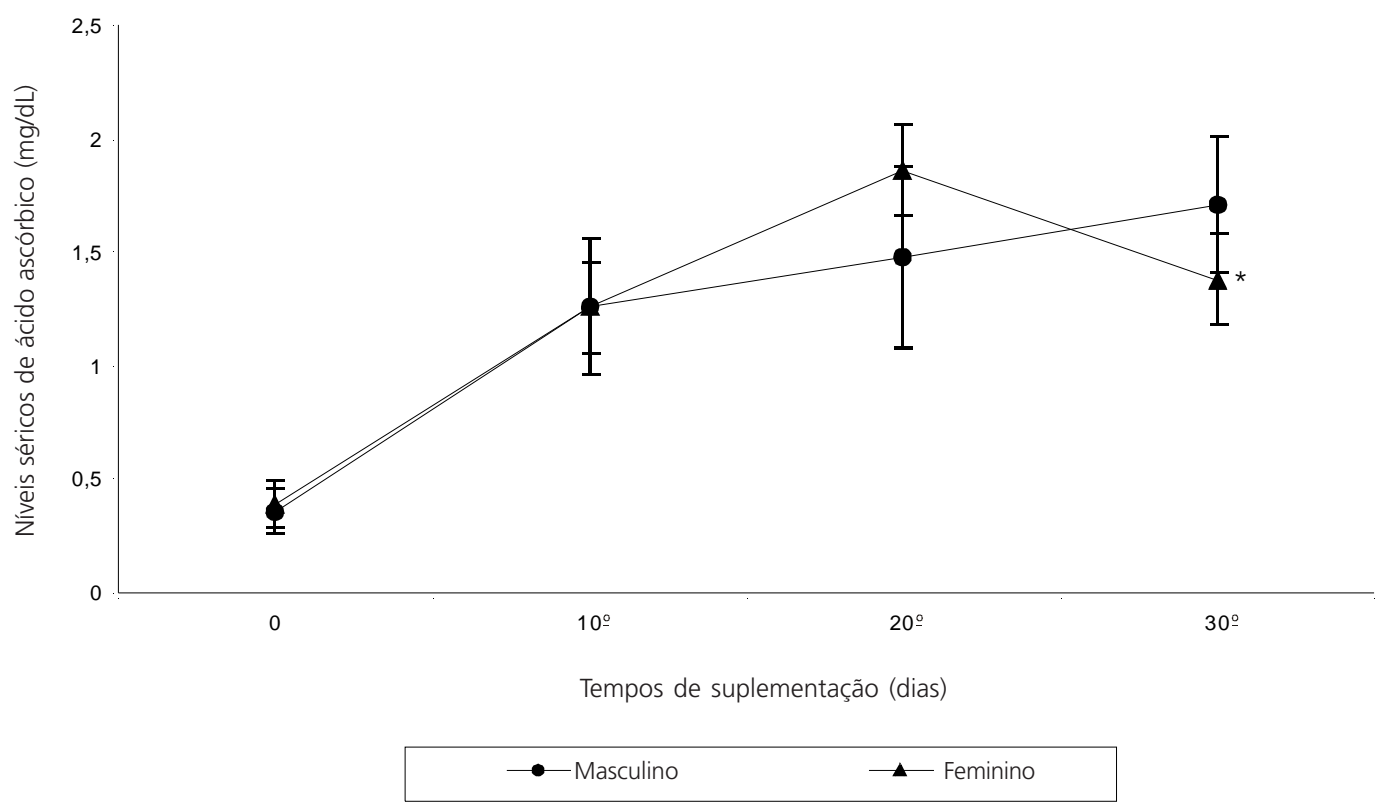

Figura 1. Evolução das médias dos níveis séricos de ácido ascórbico, por sexo, nos idosos institucionalizados, após 30 dias de suplementação com vitamina $\mathrm{C}$ por sexo.

(*) $p<0,05$ em relação ao $20^{\circ}$ dia. 
valores não diferiram significativamente. Não houve alteração significativa nos níveis séricos de ácido ascórbico, do grupo controle, durante o período de suplementação (Figura 2).

O suco de acerola, sendo uma fonte natural, pode ter ocasionado a absorção mais rápida do que a do comprimido (fonte sintética). É possível que, na acerola, a presença de flavonóides, substância encontrada nas plantas cítricas em geral, seja responsável pelo aumento da absorção de ácido ascórbico e pela sua estabilização ${ }^{11}$.

Como já foi relatado na literatura, os dois tipos de suplementos mostraram-se eficazes, uma vez que, ao se aplicar o teste de Duncan, no $30^{\circ}$ dia, os idosos suplementados apresentaram níveis superiores aos do grupo controle (Figura 2).

De acordo com Mangels et al. ${ }^{16}$, diferentes tipos de suplemento levaram a semelhantes concentrações de ácido ascórbico em indivíduos que ingeriram 108mg/dia deste, na forma de comprimido, com ou sem ferro, e com gomos ou suco de laranja, brócolis cru ou cozido. A suplementação com os dois tipos de fontes (natural e sintético) para grupos diferentes, ocorreu por um período de quatro semanas, resultando em uma biodisponibilidade semelhante advinda dos 2 tipos de suplemento.

Segundo a literatura, o limiar de saturação orgânica de ácido ascórbico é de 1,40mg/dL ${ }^{17}$. No presente estudo, o pico de concentração foi verificado no $20^{\circ}$ dia, quando a concentração média de ácido ascórbico, entre os idosos suplementados com suco de acerola, atingiu $1,67 \mathrm{mg} / \mathrm{dL}$; entre aqueles que tomaram comprimido, essa concentração foi de $1,71 \mathrm{mg} / \mathrm{dL}$.

O tempo ideal de suplementação de vitamina $C$ foi calculado com base na distribuição percentual dos idosos estudados, segundo os diferentes níveis séricos de ácido ascórbico. Verificou-se, no início do estudo, a prevalência de $38,46 \%$ de carência grave $(<0,20 \mathrm{mg} / \mathrm{dL})$ e $61,52 \%$ de carência moderada $(0,20$ a $0,80 \mathrm{mg} / \mathrm{dL}$ ). Esse quadro começou a melhorar a partir do $20^{\circ}$ dia (teste Qui-quadrado de Pearson $p=0,0654)$; no $30^{\circ}$ dia, essa melhora foi bastante

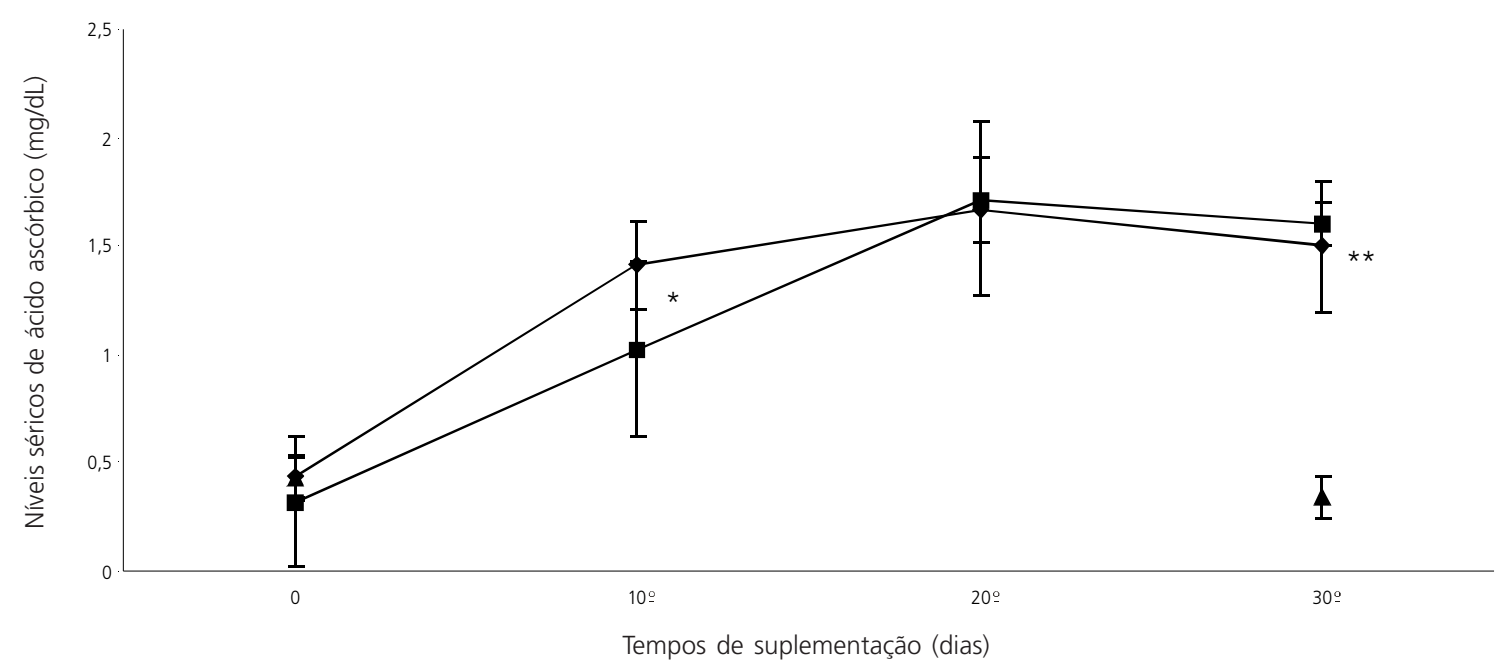

$\neg$ Suco de acerola

$\rightarrow-$ Comprimido

Controle

Figura 2. Evolução das médias dos níveis séricos de ácido ascórbico, nos idosos institucionalizados, após 30 dias de suplementação com vitamina C, considerando-se o grupo suplementado com suco de acerola, grupo do comprimido e grupo controle.

${ }^{(*)} p<0,05$ com relação à ingestão de comprimido.

${ }^{(* *)} p<0,05$ com relação aos valores iniciais. 
significativa (teste Qui-quadrado de Pearson $p=0,0180$ ), com apenas 1 idoso do sexo feminino apresentando níveis não normais e, portanto, carência moderada. Como já foi discutido anteriormente, considerando que a maioria dos idosos apresentaram níveis séricos normais após 30 dias de suplementação, isso sugere uma alteração na absorção, ou na utilização de vitamina $C$, em nível individual.

É interessante notar que, já no $20^{\circ}$ dia de suplementação, apenas 1 idoso do sexo masculino apresentou carência moderada, já com níveis muito próximos do normal $(0,78 \mathrm{mg} / \mathrm{dL})$. Esse dado reveste-se de importância indiscutível, ao se tratar de indivíduos institucionalizados que habitam asilos de poucos recursos, sem condições de oferecer- Ihes suplementação vitamínica por longos períodos. Sabendo-se que o organismo pode armazenar vitamina $\mathrm{C}$, embora por pouco tempo (cerca de 29 dias), poder-se-ia reduzir o tempo de suplementação para 20 dias, alternando-a com 20 dias de dieta livre. Tal procedimento evitaria as conseqüências renais do acúmulo de produtos de excreção da vitamina ${ }^{11}$, assim como manteria os níveis séricos satisfatórios nos indivíduos idosos. O fato de haver uma leve queda dos níveis séricos de ácido ascórbico, após o $20^{\circ}$ dia (Tabela 1), reforça esta hipótese, uma vez que tal queda parece indicar maior eliminação após saturação das suas reservas. Verificou-se que, a partir do $20^{\circ}$ dia, já não existe a relação de dependência entre a suplementação e os níveis séricos de ácido ascórbico, observada no $10^{\circ}$ dia (teste Qui-quadrado de Pearson $p=0,027$ ). Verificou-se ainda que, com doses de $180 \mathrm{mg} /$ dia ou mais, cerca de $20 \%$ de ácido ascórbico absorvido é excretado como metabolitos na urina, enquanto que, com influxos baixos, esse percentual eleva-se à cerca de $90 \%$. Mesmo com baixa ingestão (30 mg/dia), o ácido ascórbico foi excretado inalterado na urina - resultado contrário às observações feitas anteriormente, em que o ácido ascórbico fora excretado apenas após saturação de suas reservas corporais $^{12}$. O percentual de idosos com níveis séricos a partir de 0,80mg/dL, atingiu 96,10\%, após 30 dias de suplementação. Esses resultados estão de acordo com aqueles relatados por Moura et al. ${ }^{12}$, demonstrando aumento dos níveis séricos de ácido ascórbico em relação ao tempo de suplementação.

No que se refere às faixas etárias, não houve diferença significativa nos níveis séricos de ácido ascórbico $(p>0,05)$ entre elas, segundo os diferentes tempos de suplementação. Esse resultado contradiz os resultados de outras pesquisas em que se observou a relação entre esses parâmetros. Kouris-Blazos et al. ${ }^{18}$, comparou os idosos gregos que viviam em Melbourne (Austrália), aos idosos que viviam na cidade rural Spata (Grécia), observando que tanto uns como os outros, tinham níveis séricos de ácido ascórbico menores na faixa etária de 80 anos e mais. De acordo com Alencar et al. ${ }^{19}$, os idosos do Serviço de Geriatria, São Paulo, com idade acima de 80 anos, apresentaram níveis médios de vitamina $C$ menores do que aqueles nas outras faixas etárias.

\section{Consumo de vitamina $\mathrm{C}$}

A partir da avaliação do consumo de vitamina C, observou-se que $100 \%$ dos idosos carentes apresentaram risco de deficiência, ou seja, ingestão entre $50 \%$ e $80 \%$ das recomendações. Esse fato era esperado, pois se observara uma freqüência muito baixa do consumo de frutas e hortaliças (3,85\% e 3,44\%, respectivamente).

A análise do consumo alimentar mostrou uma baixa ingestão de vitamina $C$ entre os idosos estudados, sendo a média de $38,76 \pm 14,05 \mathrm{mg} /$ dia entre os homens $e$ $32,63 \pm 11,66 \mathrm{mg} /$ dia entre as mulheres, não havendo diferença significativa entre os sexos após a aplicação do teste-T $(p>0,05)$ (Tabela 2); não foi possível informar-se sobre o consumo alimentar de vitamina $C$ de um idoso do sexo feminino. Observou-se que idosos institucionalizados recebem uma refeição com padrão igual para todos, em que faltam alimentos ricos em vitamina C; isto, provavelmente se deva ao custo e/ou às exigências de maior trabalho e cuidado 
Tabela 2. Consumo médio de vitamina C, em mg/dia, entre os idosos, por sexo.

\begin{tabular}{llc}
\hline Sexo & $\mathrm{n}$ & $\overline{\mathrm{x}}$ \\
\hline Masculino & 18 & $38,76 \pm 14,05$ \\
Feminino & 18 & $32,63 \pm 11,66$ \\
\hline Total* $^{*}$ & 36 & $35,69 \pm 12,85$ \\
\hline
\end{tabular}

(*) Teste "t" não significativo $(p>0,05)$.

no preparo de produtos como frutas e hortaliças, deixando estes de fazer parte do cardápio cotidiano das instituições, e cedendo lugar principalmente aos cereais e derivados ${ }^{20}$.

Outro fato importante é a perda de vitamina $\mathrm{C}$ no preparo e cozimento dos alimentos, devido à mão-de-obra não especializada; em geral, a cozinheira e auxiliares estabelecem o cardápio, montado de acordo com a disponibilidade dos gêneros alimentícios das instituições, e realizam todas as etapas de execução do mesmo, sem orientação de uma nutricionista.

De fato, estudo realizado por Moura et al. ${ }^{12}$, revelou que o idoso institucionalizado apresenta baixos influxos de vitamina C; isto, em parte, devido à preparação e ao transporte inadequados do alimento, e, em parte, à carência de alimentos ricos em vitamina $C$ no cardápio. Isso poderia ser melhorado, utilizando-se métodos adequados de preparo dos alimentos e variando-se os cardápios das instituições.

Os dados apresentados por Guilland \& Lequeu ${ }^{11}$, indicam influxos dietéticos de vitamina $C$ mais elevados nos homens do que nas mulheres, entre indivíduos não institucionalizados. Por outro lado, Gaudenzi et al. ${ }^{14}$ verificam que as mulheres institucionalizadas, em geral, têm uma ingestão de vitamina $\mathrm{C}$ maior do que a dos homens.

De acordo com os autores Guilland \& Lequeu $^{11}$, Azevedo ${ }^{17}$ e Alencar ${ }^{19}$, a ingestão de doses elevadas de vitamina $C$ durante períodos prolongados, ao ser suspensa bruscamente, provoca no indivíduo um efeito de rebote, podendo desencadear um "escorbuto reacional", devido a uma readaptação adquirida para a hipersaturação dessa vitamina no organismo.

A dose administrada neste estudo está de acordo com aquela proposta pela Associação Médica Americana, citada por Guilland \& Lequeu ${ }^{11}$, recomendando doses de 250 a 500mg no tratamento de deficiência vitamínica C. Por outro lado, Azevedo ${ }^{17}$ sugere que, em condições normais, $200 \mathrm{mg} /$ dia são suficientes para a manutenção de um ótimo nível de saturação sangüíneo-tecidual.

O coeficiente de correlação de Pearson revelou associação significativa entre o consumo de vitamina $C$ e os níveis séricos de ácido ascórbico no tempo $0(r=0,6573 ; p=0,001)$, deixando claro que os baixos influxos levaram a níveis séricos deficientes. Ao contrário, Guilland \& Lequeu ${ }^{11}$, não verificaram correlação significativa entre os níveis séricos de vitamina $C$ e seus correspondentes níveis de ingestão. Nos demais tempos, essa associação não foi observada, podendo-se supor que uma dose superior àquela mínima para a saturação orgânica deixa de apresentar relação com os níveis séricos de ácido ascórbico.

\section{O N C L U S Ã O}

Considerando que, no $20^{\circ}$ dia, o efeito da suplementação foi satisfatório, esse tempo poderia ser utilizado para idosos em geral e, em especial, para aqueles que vivem em instituições carentes, sendo o suco de acerola o tipo indicado, por ser um produto natural e de fácil aquisição.

\section{REFERÊ NCIAS}

1. Ramos SC, Oliveira MNG. Constipação intestinal no idoso: a fibra como tratamento e prevenção. Rev Nutr Pauta 2002; 10:51-5.

2. Aranha FQ, et al. O papel da vitamina C sobre as alterações orgânicas no idoso. Rev Nutr 2000; 13:89-97.

3. Costa MJC. Statut vitaminique biochimique. Nancy: INSERM-CNRS; 1992. Rapport Techinique de 
Post-Doctoral - Université de Nancy, Center de Médicine Preventive.

4. Tsuji H, Seabra MEG, Matsubara BB, Burini RC. Efeito de idade, sexo e estresse físico sobre os níveis séricos de vitamina $C$ em indivíduos sadios. Rev Bras Patol Clin 1993; 29:83-6.

5. Pao EM, Cypel YS. Cálculo de la ingesta dietética. In: Conocimientos actuales sobre nutricion. 6th ed. Washington, DC: Organizacion Panamericana de la Salud. 1991. p.461-70.

6. Gonçalves MCR. Avaliação dietética e bioquímica do estado vitamínico A e avaliação nutricional de integrantes dos Núcleos de Idosos da Secretaria de Ação Social da Prefeitura Municipal de João Pessoa-PB [dissertação]. João Pessoa: Centro de Tecnologia, Universidade Federal da Paraíba; 1995.

7. National Research Council (USA). Recommended dietary allowances. 10th ed. Washington, DC: National Academy Press; 1989.

8. Franco G. Tabela de composição química dos alimentos. 9.ed. São Paulo: Atheneu; 1992.

9. Estudo Nacional de Despesa Familiar (ENDEF). Tabela de composição de alimentos. 3.ed. Rio de Janeiro: IBGE; 1985.

10. Moura LS. Evaluation du statut nutritionnel vitaminique $B_{1}, B_{2}, B_{6}, C$, $A$ et $E$ chez des personnes âgées en hospitalisation de longue durée [thése]. Dijon: Université de Bourgogne; 1987.

11. Guilland JC, Lequeu B. As vitaminas do nutriente ao medicamento. São Paulo: Santos; 1995.

12. Moura LS, Guilland JC, Fuchs F, Richard D. Vitamins $E, C$, thiamin, riboflavin and vitamin $B_{6}$ status of institutionalized elderly including the effects of supplementation. Nutr Res 1993; 13:1379-92.
13. Levine $M$, Dhariwal KR, Welch RW, Wang Y, Park JB. Determination of optimal vitamin C requirements in humans. Am J Clin Nutr 1995; 62:S1347-56

14. Gaudenzi EN, Silva IS, Carvalho MFA. Avaliação do estado nutricional de idosos residentes no abrigo D. Pedro II - Salvador. Rev Baiana Saude Publica $1991 ; 18: 75-84$.

15. Costa MJC, Guilland JC, Moreau D. Vitamin status of healthy subjects in Burgundy (France). Ann Nutr Metab 1996; 40:24-51.

16. Mangels $A R$, et al. The biovailability to humans of ascorbic acid from oranges, orange juice and cooked broccoli is similar to that of synthetic ascorbic acid. J Nutr 1993; 123:1054-61.

17. Azevedo BA. Vitamina C (ácido ascórbico) de liberação lenta e rápida. Prat Med 1983; $87: 287-9$.

18. Kouris-Blazos A, Wahlquist ML, Trichopoulou A. Health and nutritional status of elderly greek migrants to Melbourne, Austrália. Age Ageing 1996; 25:177-89.

19. Alencar YMG, Roncada MJ, Okani ET. Vitamin C plasma levels in the elderly. Gerontologia 1993; $1: 85$.

20. Simões MOS. Efeitos da suplementação em vitamina C, da acerola e do fármaco sobre os níveis séricos de ácido ascórbico em idosos institucionalizados do Município de João Pessoa - PB [dissertação]. João Pessoa: Centro de Tecnologia, Universidade Federal da Paraíba; 1997.

Recebido para publicação em 18 de outubro de 2001 e aceito em 5 de novembro de 2003. 
